\title{
Power Quality Enhancement by Optimally Placing the UPQC in the Distribution System: A Hybrid Optimization Model
}

\section{SK.Mahammad Shareef}

Narasaraopeta Engineering College,

Guntur, Andhra Pradesh, India

mahammadshareef.sk01@gmail.com

\begin{abstract}
Recently, there is a greater demand for the electricity and at the same time modern equipments utilized in the distribution system are more sensitive to distortions. Therefore, the power electronic devices like FACTS are considerably gaining a huge attention for enhancing the power quality. The UPQC is a FACTS device that can function as DSTATCOM and DVR for shunt and series compensators, respectively. Therefore, the Optimal placement of UPQC is considered as a solution to reach the goal of optimal operation in the distribution systems and power quality enhancement. In this research work, the Grasshopper Optimization with Genetic Algorithm (GOAGA) is utilized for optimally placing and sizing of UPQC in distribution system. To achieve the objective of optimal placement, the multi-objectives likes "minimization of cost, loss and Voltage Stability Index" need to be satisfied. The performance of the proposed optimal placement model of UPQC with GOAGA model is compared over the other state-of-art models to exhibit the superiority of the proposed work. The location accuracy of UPQC with GOAGA is 800 at $250 \%$ loading condition, while the location accuracy of UPQC with GOA, GA, GWO and $\mathrm{ABC}$ is $740.81 \%, 430 \%, 720 \%$ and $780 \%$, respectively.
\end{abstract}

Keywords: UPQC; Optimal Placement and Sizing; FACTS device; Voltage Stability Index, GOAGA

\begin{tabular}{ll} 
Nomenclature & \\
\hline Abbreviations & Descriptions \\
\hline ABC & Artificial Bee Colony \\
CSA & Crow Search Algorithm \\
CPD & Custom power devices \\
CSM-LA & Crow Search Mating-Based Lion Algorithm \\
DA & Dragonfly Algorithm \\
DFACTS & Distribution Network Flexible Alternating Current Transmission Systems \\
DSTATCOM & Distribution Static Compensator \\
FACTS & Flexible Alternating Current Transmission Systems \\
GA & Genetic Algorithm \\
GOA & Grasshopper Optimization Algorithm \\
GOAGA & Grasshopper Optimization With Genetic Algorithm \\
GWO & Grey Wolf Optimization \\
LA & Lion Algorithm \\
PQ & Power Quality \\
PSO & Particle Swarm Optimization \\
PLI & Power Loss Index \\
PFL & power flow limit \\
UPQC & Unified Power Quality Conditioner \\
UPQC-O & Open Unified Power Quality Conditioner \\
VSI & Voltage Stability Index \\
VML & voltage magnitude limit \\
VUL & voltage unbalance limit \\
VSC & voltage source converter \\
\hline
\end{tabular}




\section{Introduction}

A significant attention is being gained by the distribution systems in maintaining the voltage magnitude and Power quality within the acceptable range. The power system operation in the transmission and distribution systems is guided by the FACTS [6-10]. In the distribution systems, the DFACTS are utilized and the prominent devices among DFACTS are the UPQC, DSTATCOM and Dynamic Voltage Restorer. Among all these the UPQC is the most preferred DFACTS device, as it is good in solving the current-related problems and voltage mitigation in distribution systems. Two major components of UPQC [11-15] are: "(i) shunt compensator and (ii) series compensator". A series voltage is injected by the "UPQC series compensator" that aids in swell and sag mitigation in the supply voltage. The shunt compensator provides two main functions: a shunt compensating current injection into the load for providing load reactive power and load harmonic distortion compensations.

The electrical demand is increasing day by day. The count of nonlinear load is increasing in the CPDs and this tends to degrade the "power quality" of the distribution system [16-20]. As a solution to this, the optimal operation of distribution network needs to be given much attention. In order to reach this goal, the UPQC placement and sizing for the reactive power compensation is suggested as a promising solution.

There were 3 techniques for reducing voltage sags. They are "UPQC-Q, UPQC-P and minimum VA loading of UPQC". In the aforesaid techniques, the lessening of voltage sag with phase jumps is for the positive sequence voltage. Usually, voltage sag is characterized by sag depth, phase jump and duration of sag. But, most of the voltage sags are deep and long duration sag which has negative impact when compared to shallow and short duration sags on sensitive loads. The optimization algorithms play a key role in finding the optimal UPQC location.

The major contribution of this research work is:

$\checkmark$ To propose a power quality improvement by means of placing the UPQC device optimally with the aid of the GOAGA model. The GOAGA model is the conceptual improvement of GA and GOA, respectively.

$\checkmark$ To achieve the objective of optimal placement, the multi-objectives likes "minimization of cost, loss and Voltage Stability Index" need to be satisfied.

The rest of the paper is organized as: section 2 describes the literature works undergone in UPQC placement. Section 3 describes about Power Quality Enhancement with UPQC: Modelling, Objective Function and Constraints. The results acquired with the proposed work are discussed in Section 4 . Finally, a strong conclusion is given to this research work in Section 5.

\section{Literature Review}

\subsection{Related Works}

In 2020, Gaddala \& Raju [1] have proposed a "new power quality improvement model" by placing the UPQC optimally in the power system. The optimal placement was accomplished with Genetically Modified DA algorithm, which was a conceptual blending of both the DA and GA. the optimal location was identified on the basis of certain objectives like "UPQC cost, power losses, and Voltage stability Index". They have tested the proposed model on "IEEE 69, and IEEE 33 test bus systems" to shows the efficiency of the proposed work.

In 2017, Gupta \& Kumar [2] have presented an efficient model for optimum location identification of D-STATCOM and UPQC in the "radial distribution system". The optimal location was found using the PLI method and the bus with highest PLI was said to be the most favorable bus. They have tested the proposed model on "IEEE 33-bus and 69-bus radial distribution systems ".

In 2020, Gaddala \& Raju [3] have proffered a nonlinear multi-objective function for "optimal sizing and localization of UPQC in the power system". The nonlinear multi-objective function encloses the objectives like "minimization of power loss, UPQC cost and VSI" and these objectives were achieved with CSM-LA, which was the conceptual amalgamation of LA and CSA. The "IEEE 33 and IEEE 69 benchmark test bus systems" were utilized for testing the proposed work.

In 2017, Lakshmi and Ganguly [4] have developed a new planning model based on PSO for incorporating the UPQC-O into the power system for enhancing the PQ and losses. The reactive power compensation as provided by the shunt inverter after the elimination of the harmonics generated by the load. The objective behind the current research work was the minimization of the "energy loss under the voltage, thermal overloading, and the desirable PQ constraints". 
In Sharma and Kumar [5] have proposed a new methodology for PQ improvement by means of compensating the reactive power during the placement of UPQC. This optimal placement was based on the development of the new sensitivity index. The results from the proposed model had exhibited its superiority in tersm of power quality.

\section{Power Quality Enhancement with UPQC: Modelling, Objective Function and Constraints}

\subsection{Objective Function}

The major objective behind this research work is to enhance the power quality by means of placing the UPQC in an appropriate position. The objective function is shown in Eq. (1).

$$
\mathrm{OB}=\min \left(\mathrm{UPQC}_{\text {cost }}+\mathrm{VSI}+\mathrm{Loss}\right)
$$

The VSI formula is shown in Eq. (2), in which $\mathrm{Vol}^{\min }, \mathrm{Vol}^{\mathrm{max}}$ and $\mathrm{Vol}^{\mathrm{b}}$ are the minimum bus voltage, maximal bus voltage and the voltage of the $\mathrm{b}^{\text {th }}$ bus respectively. The VSI is fixed within the range 0.9 to 1.1

$$
\text { VSI }=\left\{\begin{array}{ll}
1 & \text { if } \operatorname{Vol}^{\min } \leq \operatorname{Vol}^{\mathrm{b}} \leq \mathrm{Vol}^{\max } \\
\exp \left(\mu\left|1-\operatorname{Vol}^{\mathrm{b}}\right|\right) & \text { otherwise }
\end{array}\right\}
$$

In addition, the mathematical formula for loss is expressed in Eq. (3).

$$
\text { Loss }=\sum_{k=1}^{N_{L}} \operatorname{Loss}_{k}=\sum_{k=1}^{N_{L}} O_{k}\left\{\left(V_{i}^{2}+V_{j}^{2}-2 V_{i} V_{j} \cos \left(\delta_{i}-\delta_{j}\right)\right\}\right.
$$

The UPQC cost is mathematically expressed as per Eq. (4)

$$
\begin{aligned}
& \mathrm{UPQC}_{\text {cost }}(\mathrm{US}(\$ / \mathrm{kVAr}))=0.0003 \mathrm{O}^{\text {range }}{ }^{2}-0.26910^{\text {range }}+188.22 \\
& \mathrm{UPQC}_{\text {Costyear }}=\mathrm{UPQC}_{\text {Cost }} \frac{(1-\text { Rate })^{\mathrm{mUPQC}} \times \text { Rate }}{(1+\text { Rate })^{\mathrm{mUPC}}-1}
\end{aligned}
$$

Here, Rate refers to the asset rate of return and $\mathrm{O}^{\text {range }}$ is the "operating range of UPQC in MVAr". The UPQC investment cost and annual cost is denoted as $\mathrm{UPQC}_{\text {Cost }}$ and $\mathrm{UPQC}_{\text {Cost }_{\text {year }}}$, respectively. The longevity of UPQC is represented as mUPQC .

In order to achieve the aforementioned objective function, certain constraints need to be satisfied.

\subsection{Equality and Inequality Constraints}

Inequality Constraints: The operational limits and the potential of the system are expressed under the inequality constraints.

(a) Bus voltage limit-The mathematical formula for "3-phase node voltage magnitude limit constraint" in terms of VML and VUL is shown in Eq. (5).

$$
\mathrm{V}^{\min }<\mathrm{V}<\mathrm{V}^{\max }
$$

(b) Line flow limit-The mathematical formula for PFL is expressed in Eq. (6), in which $\mathrm{P}_{\text {flow(k) }}$ power flow via the $\mathrm{k}^{\text {th }}$ line.

$$
\mathrm{P}_{\text {flow(k) }} \leq \mathrm{P}_{\text {flow }(\mathrm{k} \max )}
$$

Equality Constraints: The active line power is represented in terms of "voltage magnitude of the bus", while the reactive line power is described in terms of phase angle of bus. In the "distribution system", the "active power balance" is expressed as per Eq. (7), in which Pactive $\mathrm{H}_{\mathrm{H}_{\mathrm{i}}}$ is the injected active power at $\mathrm{i}^{\text {th }}$ bus and Pactive $\mathrm{E}_{\mathrm{i}}$ is the system active power demand.

$$
\text { Pactive }_{\mathrm{H}_{\mathrm{i}}}-\text { Pactive }_{\mathrm{E}_{\mathrm{i}}}-\sum_{\mathrm{k}=1}^{\mathrm{N}_{\mathrm{L}}} \mathrm{o}_{\mathrm{ik}}\left\{\begin{array}{l}
\mathrm{Vol}_{\mathrm{i}}^{2}+\mathrm{Vol}_{\mathrm{j}}^{2}- \\
-2 \mathrm{Vol}_{\mathrm{i}} \mathrm{Vol}_{\mathrm{j}} \cos \left(\delta_{\mathrm{i}}-\delta_{\mathrm{j}}\right)
\end{array}\right\}=0
$$

In addition, the reactive power balance is mathematically defined as per Eq. (8). Here, Qreact $_{\mathrm{H}_{\mathrm{i}}}$ is the injected reactive power at $\mathrm{i}^{\text {th }}$ bus and Qreact $_{\mathrm{E}_{\mathrm{i}}}$ is the reactive power demand. In addition, $\mathrm{O}_{\mathrm{ik}}$ and $\mathrm{p}_{\mathrm{ik}}$ are the conductance and susceptance between $\mathrm{i}^{\text {th }}$ and $\mathrm{j}^{\text {th }}$ bus, respectively. The magnitude of the voltage at the $i^{\text {th }}$ and $j^{\text {th }}$ bus is denoted as $\mathrm{Vol}_{\mathrm{i}}$ and $\mathrm{Vol}_{j}$, respectively. 


$$
\operatorname{Qreact}_{\mathrm{H}_{\mathrm{i}}}-\text { Qreact }_{\mathrm{E}_{\mathrm{i}}}-\sum_{\mathrm{k}=1}^{\mathrm{N}_{\mathrm{L}}} \mathrm{p}_{\mathrm{ik}}\left\{\begin{array}{l}
\mathrm{Vol}_{\mathrm{i}}^{2}+\mathrm{Vol}_{\mathrm{j}}^{2}- \\
-2 \operatorname{Vol}_{\mathrm{i}} \mathrm{Vol}_{\mathrm{j}} \sin \left(\delta_{\mathrm{i}}-\delta_{\mathrm{j}}\right)
\end{array}\right\}=0
$$

On the basis of these equality and non-equality constraints the UPQC is modelled appropriately in the system model.

\subsection{Modelling of UPQC}

The UPQC in the form of a 3-phase four wire VSC with a "series APF and shunt APF" is shown in Fig.1. The issues related to the current like the power factor improvement, compensation in "current harmonic, compensation in reactive power, compensation in load unbalance and dc link voltage regulation" are solved by means of connecting the shunt APF across the load. The series APF is connected with the line in a series combination and this is accomplished via a "3-phase series transformer". This 3-phase series transformer acts as a "controlled voltage source" and compensates the voltage associated issues like the "flicker, voltage harmonics" as well. The load disturbance area is minimized with the fault protection and hence makes it function as a normal operating zone. a single dc storage capacitor connected between two inverters, in which on inverter is utilized for "series voltage insertion" and the other for the shunt current injection.

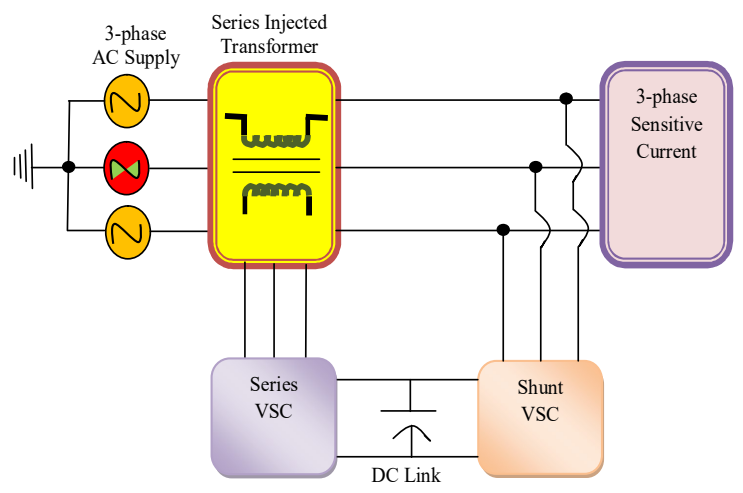

Fig. 1. UPQC Diagrammatic Representation

The series inverter and the shunt inverter works on the principle as:

The magnitude of the source voltage in the normal condition is described as $\mathrm{Vol}_{\mathrm{s}}=\mathrm{Vol}_{\mathrm{SO}}$ and voltage sag condition is described as $\mathrm{Vol}_{\mathrm{s}}=\mathrm{k}_{\mathrm{sag}} \mathrm{Vol}_{\mathrm{SO}}$.

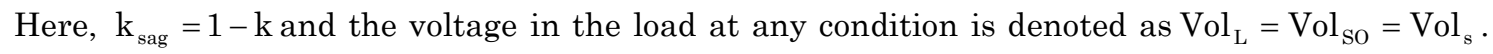
The mathematical formula for injection of the series voltage for $\mathrm{k}_{\mathrm{sag}}$ mitigation is shown in Eq. (9).

$$
\begin{aligned}
\mathrm{Vol}_{\mathrm{se}} & =\sqrt{\mathrm{Vol}_{\mathrm{L}}^{2}+\left(\mathrm{kVol}_{\mathrm{SO}}\right)^{2}-2 \mathrm{Vol}_{\mathrm{L}}\left(\mathrm{kVol}_{\mathrm{SO}}\right) \cos \delta} \\
& =\mathrm{V}_{\mathrm{s}} \sqrt{1+\mathrm{k}^{2}-2 \mathrm{k} \cos \delta}
\end{aligned}
$$

Then, for a lossless UPQC, the demanded active power by load is the active power drawn from source. Here, $\mathrm{Ics}_{\mathrm{s}} \cdot \mathrm{k} \cdot \mathrm{Vol}_{\mathrm{s}}=\mathrm{Ics}_{\mathrm{L}} \cdot \mathrm{Vol}_{\mathrm{L}} \cos \phi$ and $\mathrm{Ics}_{\mathrm{s}}$ is the compensated source-end current and $\mathrm{Ics}_{\mathrm{L}}$ is the compensated load current. In the series inverter, the VA rating is defined as per Eq. (11) and it is acquired from Eq. (10) and Eq. (9), respectively.

$$
\begin{aligned}
& \mathrm{Ics}_{\mathrm{s}}=\mathrm{Ics}_{\mathrm{L}} \cos \phi / \mathrm{k} \\
& \mathrm{SE}_{\mathrm{se}}=\mathrm{Vol}_{\mathrm{se}} \mathrm{Ics}_{\mathrm{s}}=\mathrm{Vol}_{\mathrm{s}} \mathrm{Ics}_{\mathrm{L}} \cos \phi \sqrt{\mathrm{k}^{2}+1-2 \mathrm{k} \cos \delta / \mathrm{k}}
\end{aligned}
$$

The series inverter that is fed with the active and the reactive power is described as per Eq. (12).

$$
\text { Pactive }_{\mathrm{Se}}=\mathrm{SE}_{\mathrm{se}} \cos \theta_{\mathrm{se}}
$$

In which,

$$
\begin{aligned}
& \theta_{\mathrm{se}}=180^{\circ}-\tan ^{-1}(\sin \delta / 1-\cos \delta) \\
& \text { Qreact }_{\mathrm{se}}=\mathrm{SE}_{\mathrm{se}} \sin \theta_{\mathrm{se}}
\end{aligned}
$$

The compensating current is expressed as per Eq. (15) and it is acquired via the $\operatorname{Ics}_{\mathrm{sh}}$ 


$$
\begin{aligned}
& \mathrm{Ics}_{\mathrm{sh}}=\sqrt{\mathrm{Ics}_{\mathrm{s}}^{2}-2 \mathrm{Ics}_{\mathrm{s}} \mathrm{Ics}_{\mathrm{L}} \cos (\phi-\delta)} \\
& \quad=\mathrm{I}_{\mathrm{L}} \sqrt{1+\cos ^{2} \phi / \mathrm{k}^{2}-2 \cos \phi \cos (\phi-\delta) / \mathrm{k}}
\end{aligned}
$$

At the load end, the harmonic are compensated by the shunt inverter and this is mathematically shown in Eq. (16), Eq. (17), respectively.

$$
\begin{aligned}
& \operatorname{Ics}_{\mathrm{L}}^{\text {dist }}=\operatorname{Ics}_{\text {sh }}^{\text {dist }} \\
& \operatorname{Ics}_{\mathrm{L}}^{\text {fun }} \cdot \operatorname{THD}_{\mathrm{L}}=\operatorname{Ics}_{\text {sh }}^{\text {fun }} \cdot \operatorname{THD}_{\text {sh }}
\end{aligned}
$$

In which, the distortion and the fundamental component is denoted as $\mathrm{I}_{\mathrm{L}}^{\text {dist }}$ and $\mathrm{I}_{\mathrm{L}}^{\mathrm{fun}}$, respectively. The THD load current is $\mathrm{THD}_{\mathrm{L}}$ and the shunt inverter's distortion and the fundamental component is denoted as $\mathrm{I}_{\text {sh }}^{\text {dist }}$ and $\mathrm{I}_{\mathrm{sh}}^{\mathrm{fun}}$, respectively. In addition $\mathrm{THD}_{\mathrm{sh}}$ is the shunt inverter current's THD. The r.m.s value corresponding to the current of the shunt compensation is determined as per Eq. (18).

$$
\begin{aligned}
\operatorname{Ics}_{\mathrm{sh}} & =\operatorname{Iss}_{\mathrm{sh}}^{\mathrm{fu}} \sqrt{1+\mathrm{THD}_{\mathrm{sh}}^{2}} \\
& =\mathrm{Iss}_{\mathrm{L}}^{\mathrm{fu}} \sqrt{1+\mathrm{THD}_{\mathrm{L}}^{2}+\cos ^{2} \phi / \mathrm{k}^{2}-2 \cos \phi \cos (\phi-\delta) / \mathrm{k}}
\end{aligned}
$$

The VA rating of the shunt inverter is given in Eq. (19).

$$
\begin{aligned}
\mathrm{SE}_{\mathrm{sh}} & =\mathrm{Vol}_{\mathrm{s}} \mathrm{Ics}_{\mathrm{sh}} \\
& =\mathrm{Vol}_{\mathrm{s}} \mathrm{Ics}_{\mathrm{L}}^{\text {fu }} \sqrt{1+\mathrm{THD}_{\mathrm{L}}^{2}+\cos ^{2} \phi / \mathrm{k}^{2}-2 \cos \phi \cos (\phi-\delta) / \mathrm{k}}
\end{aligned}
$$

The shunt inverter derives the active and reactive powers shown in Eq. (20) and Eq. (21), respectively.

$$
\begin{aligned}
& \text { Pactive }_{\mathrm{sh}}=\mathrm{SE}_{\mathrm{sh}} \cos \theta_{\mathrm{sh}} \\
& \text { Qreact }_{\mathrm{sh}}=\mathrm{SE}_{\mathrm{sh}} \sin \theta_{\mathrm{sh}} \\
& \text { Qreact }_{\mathrm{UPQC}}=\text { Qreac }_{\mathrm{se}}+\text { Qreac }_{\mathrm{sh}}
\end{aligned}
$$

Here,

$$
\theta_{\mathrm{sh}}=\tan ^{-1}\{\cos (\phi-\delta)-\cos \phi / \sin (\phi-\delta)\}+90^{\circ}-\delta
$$

To achieve the objective of enhancement power quality, the optimal placement in terms of sizing and positing of on the bus system need to be placed appropriately. In this research work, the UPQC is implemented in IEEE 33 bus system and IEEE 69 bus system, such that the optimal placement in terms of sizing and positing of UPQC is fed as solution to the GOAGA model.

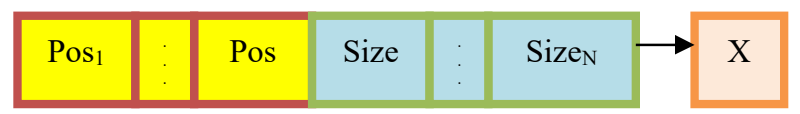

Fig. 2. Solution Encoding

\subsection{GOAGA Algorithm}

GA is a heuristic optimization method that is generally employed for improve the solutions and for solving the multi-objective problems. But, the convergence speed of GA is lower. In addition, the GOA model is an optimization algorithm that is based on the behaviour of grasshopper swarms in nature. The convergence speed of GOA is higher and at the same time the accuracy of detecting the solutions is higher. Therefore, the GA and GOA are amalgamated to form the GOAGA model. The steps followed in the GOAGA model [26] is depicted below:

Step 1: Initialize $\mathrm{Pop}_{\mathrm{i}}$ (the random population), current iteration $\mathrm{t}$, maximum value $\mathrm{cmx}$, minimum value cmn and maximum number of iterations $L$.

Step 2: Compute the fitness of search agent

Step 3: The best search agent is considered as $\mathrm{T}$

Step 4: While $(\mathrm{t}<\mathrm{L})$ move to the following steps

Step 5: the parameter $\mathrm{c}$ is updated as per Eq. (24)

$$
\mathrm{c}=\mathrm{cmx}-\mathrm{t} \frac{\mathrm{cmx}-\mathrm{cmn}}{\mathrm{L}}
$$

Step 6: For (each search agent), the distance between the grasshoppers is stabilized in [1,4] interval.

Step 7: The position of the current search agent is updated using Eq. (25)

$$
\operatorname{Pos}_{1}^{a}=c\left(\sum_{\substack{j=1 \\ j \neq 1}}^{M} c \frac{U_{p p e r}-\text { Lower }}{2} r\left(\left|X_{j}^{a}-X_{i}^{a}\right|\right) \frac{X_{j}-X_{i}}{a_{i j}}\right)+\hat{T}_{a}
$$


Here, $a_{i j}$ is the distance between $i^{\text {th }}$ and the $j^{\text {th }}$ grasshopper and it is defined as $a_{i j}=\left|X_{j}-X_{i}\right|$. In addition, $r$ strength of the social forces and $M$ is the count of grasshoppers.

Step 7: Compute fitness using Eq. (1)

Step 8: On the basis of minimal fitness, the best two solutions are found

Step 9: Update the position of the search agent using the cross-over of GA and again Compute fitness using Eq. (1). The best two solutions acquired from GA and GOA is combined. Again compute fitness and bring the search agent to its original location.

Step 10: Terminate

\section{Results and Discussion}

\subsection{Simulation Procedure}

The proposed model for optimal placement of UPQC is implemented in MATLAB. In this research work, the proposed model is implemented in "IEEE 69 bus system and IEEE 33 bus system". This evaluation is done by varying the load conditions from " $0 \%, 50 \%, 100 \%, 150 \%, 200 \%$, and $250 \%$ respectively". The proposed model is compared over the existing models like GOA [21], GA [22], GWO [23] and ABC [24], respectively.

\subsection{Performance Analysis On IEEE 33 Bus System}

The performance of the proposed model in terms of localization accuracy with GOAGA is evaluated for 3 different locations Loc1,Loc 2 and Loc 3 , respectively. The resultant acquired for Loc1,Loc 2 and Loc 3 is shown graphically in Fig.3. In Fig. 3(a) corresponding to Loc1, at Loading $=50 \%$, the location accuracy of UPQC with GOAGA is 642.22, while the location accuracy of UPQC with GOA, GA, GWO and ABC is $599.91,561.09,515.15$ and 556.8, respectively. In addition, at location 2 , the location accuracy of UPQC with the GOAGA is the highest for every variation in the loading percentage. On observing the $150 \%$ of loading condition of loading, the GOAGA model is $0.84 \%, 0.56 \%, 0.47 \%$ and $0.28 \%$ better than location accuracy of UPQC with GOA, GA, GWO and ABC, respectively. In Fig. 3(c), the location accuracy of UPQC is higher for every variation in the loading percentage. Therefore, from the evaluation it is clear that with GOAGA, the location accuracy of UPQC is higher and hence the power quality is improved.

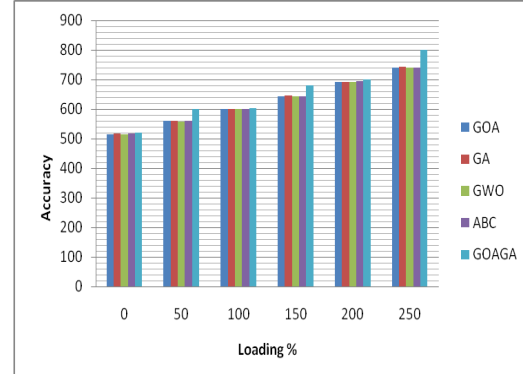

(a)

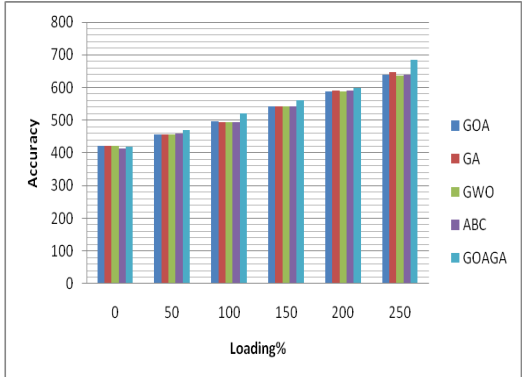

(b)

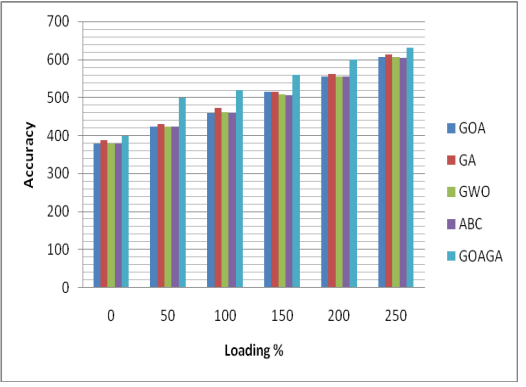

(c)

Fig. 3. Performance analysis of the location accuracy of UPQC under varying loading percentage for IEEE-33 bus sytem showing (a) Location 1,(b) Location 2 and (c) Location 3

\subsection{Performance Analysis on IEEE 69 Bus System}

The performance analysis of the proposed model with GOAGA and other existing models is shown in Fig. 4 for different locations Loc1,Loc 2 and Loc 3 , respectively. In all the three locations, the location accuracy of UPQC with GOAGA is higher. In Fig. 4(a), the location accuracy of UPQC with GOAGA is 800 at $250 \%$ loading condition, while the location accuracy of UPQC with GOA, GA, GWO and ABC is $740.81 \%, 430 \%$, $720 \%$ and $780 \%$, respectively. In addition, the location accuracy of UPQC with GOAGA for location 2 in Fig. 4(b) is higher for all the variation in the loading \%. The location accuracy of UPQC with GOAGA is the highest at $200 \%$ of loading condition and it is $10 \%, 12 \%, 8.5 \%$ and $16 \%$ better than the GOA, GA, GWO and ABC, respectively. In Fig. 4(c), the location accuracy of UPQC with GOAGA is the highest. Therefore, from the evaluation, it is clear that the optimal placement of UPQC for power quality enhancement can be acquired with GOAGA, a hybridized model. 


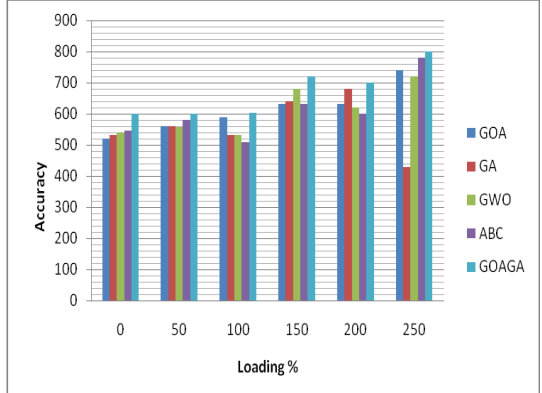

(a)

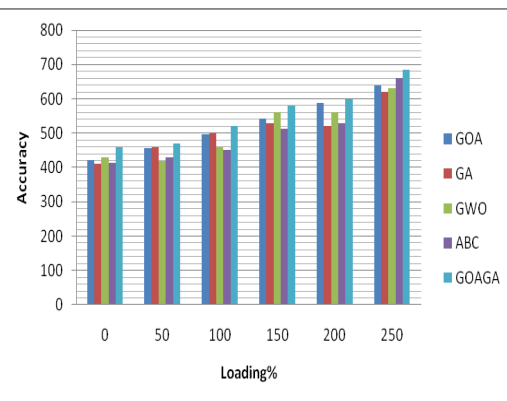

(b)

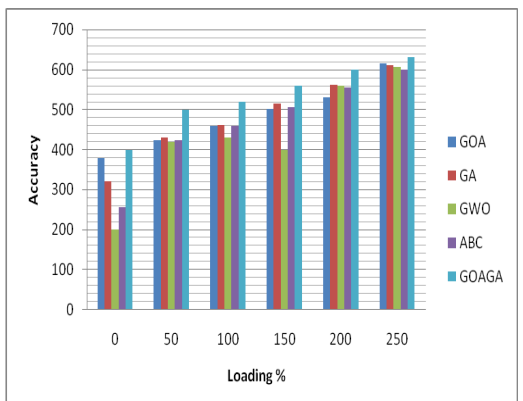

(c)

Fig. 4. Performance analysis of the location accuracy of UPQC under varying loading percentage for IEEE-69 bus sytem showing (a) Location 1,(b) Location 2 and (c) Location 3

\subsection{Overall Fitness Evaluation}

The overall fitness evaluation for "IEEE 33 bus system and IEEE 69 bus system" is shown in Table I and Table II, respectively. From the tables it is vivid that the proposed model with GOAGA based optimal placement of UPQC has achieved the single as well as multi-objectives in an efficient manner.

Table 1. Overall Fitness of the proposed UPQC placement with GOAGA and other optimization algorithms for IEEE33 bus system

\begin{tabular}{|c|c|c|c|c|c|c|c|c|c|c|c|c|}
\hline \multirow{4}{*}{ Methods } & \multirow{2}{*}{\multicolumn{3}{|c|}{ Multi-objective Fitness }} & \multicolumn{9}{|c|}{ Single Objective } \\
\hline & & & & \multicolumn{3}{|l|}{ VSI } & \multicolumn{3}{|c|}{ UPQC } & \multicolumn{3}{|l|}{ Loss } \\
\hline & $1^{\text {st }}$ & $2^{\text {nd }}$ & $3^{\text {rd }}$ & $1^{\text {st }}$ & $2^{\text {nd }}$ & $3^{\mathrm{rd}}$ & $1^{\text {st }}$ & $2^{\text {nd }}$ & $3^{\text {rd }}$ & $1^{\text {st }}$ & $2^{\text {nd }}$ & $3^{\text {rd }}$ \\
\hline & location & location & location & location & location & location & location & location & location & location & location & location \\
\hline $\begin{array}{l}\text { GOA based optimal } \\
\text { placement of UPQC }\end{array}$ & 515.4 & 420.85 & 378.17 & 34.105 & 33.856 & 34.105 & 192.42 & 108.61 & 73 & 272.27 & 21.966 & 272.3 \\
\hline $\begin{array}{l}\text { GA based optimal } \\
\text { placement of UPQC }\end{array}$ & 420.27 & 420.27 & 420.27 & 33 & 34.105 & 30.753 & 281.41 & 108.28 & 75 & 281.41 & 22.308 & 272.27 \\
\hline $\begin{array}{l}\text { GWO based optimal } \\
\text { placement of UPQC }\end{array}$ & 515.15 & 420.27 & 379.68 & 33.856 & 33.856 & 33.856 & 192.42 & 108.55 & 75.568 & 272.27 & 21.967 & 273.73 \\
\hline $\begin{array}{l}\text { ABC based optimal } \\
\text { placement of UPQC }\end{array}$ & 420.27 & 412.36 & 420.27 & 30.382 & 30.074 & 34.105 & 281.41 & 110.02 & 75.75 & 272.27 & 22.317 & 272.27 \\
\hline $\begin{array}{l}\text { GOAGA based } \\
\text { optimal placement of } \\
\text { UPQC }\end{array}$ & 410 & 408 & 370 & 36.788 & 38.381 & 37.108 & 108.55 & 107.72 & 70 & 185.88 & 21.977 & 261.41 \\
\hline
\end{tabular}

Table 2. Overall Fitness of the proposed UPQC placement with GOAGA and other optimization algorithms for IEEE69 bus system

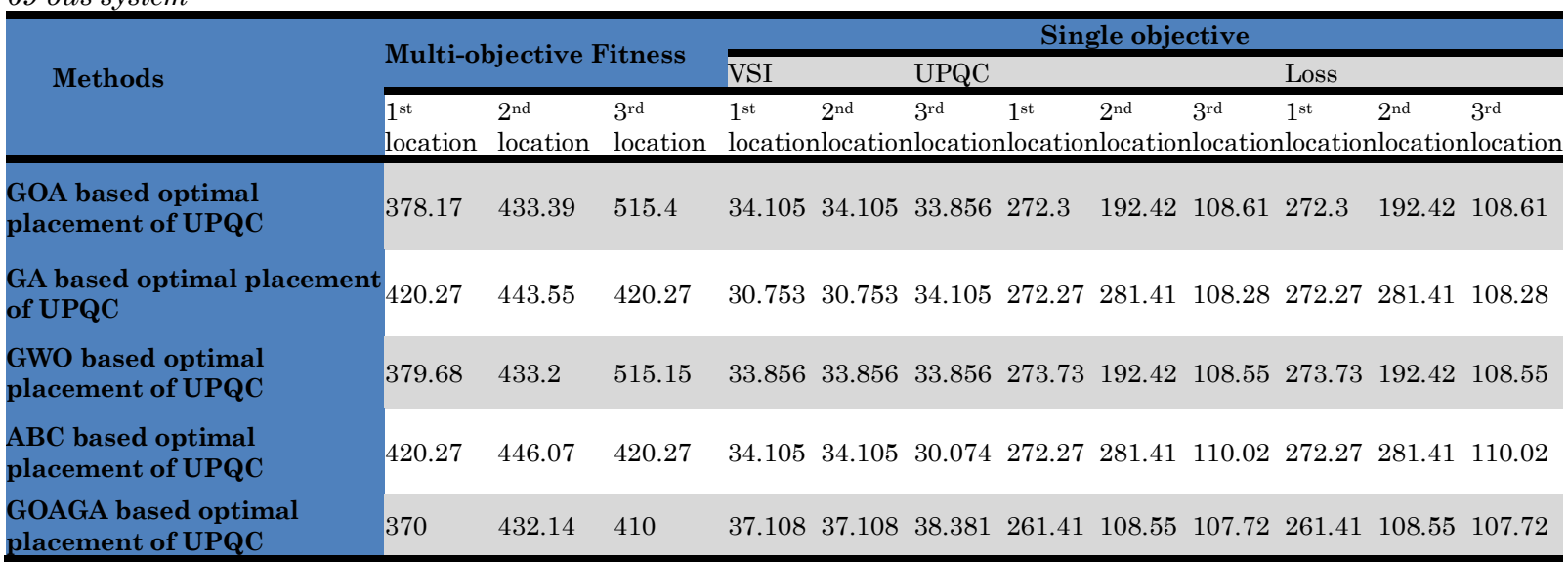

\section{Conclusion}

A power quality improvement model was developed in this research work by means of placing the UPQC device optimally with the aid of the GOAGA model. The GOAGA model is the conceptual improvement of GA and GOA, respectively. For optimally placing the UPQC in the DS, the objective like "the power system losses, UPQC cost, and Voltage stability Index" need to be satisfied. The proposed model is tested 
in "IEEE 33 and 69 bus systems" and the resultant acquired was evaluated in terms of location based performance accuracy. The location accuracy of UPQC with GOAGA is 800 at $250 \%$ loading condition, while the location accuracy of UPQC with GOA, GA, GWO and ABC is $740.81 \%, 430 \%, 720 \%$ and $780 \%$, respectively. In addition, the location accuracy of UPQC with GOAGA for location 2 in IEEE-69 bus system. Thus, the presented model has satisfied the objective function in an optimal way when evaluated over the existing works.

\section{Compliance with Ethical Standards}

Conflicts of interest: Authors declared that they have no conflict of interest.

Human participants: The conducted research follows the ethical standards and the authors ensured that they have not conducted any studies with human participants or animals.

\section{References}

[1] Kaladhar Gaddala \& P. Sangameswara Raju,"Optimal UPQC location in power distribution network via merging genetic and dragonfly algorithm", Evolutionary Intelligence,2020.

[2] Atma Ram Gupta \& Ashwani Kumar,"Performance Analysis of Radial Distribution Systems with UPQC and D-STATCOM", Journal of The Institution of Engineers (India): Series B, vol.98, Pp.415$422,2017$.

[3] Kaladhar Gaddala \& P. Sangameswara Raju,"Merging Lion with Crow Search Algorithm for Optimal Location and Sizing of UPQC in Distribution Network", Journal of Control, Automation and Electrical Systems volume, Vol.31,pp.377-392,2020.

[4] S. Lakshmi and S. Ganguly, "Energy loss minimization with open unified power quality conditioner placement in radial distribution networks using particle swarm optimization," ICPS, Pune, 2017.

[5] A. Sharma and A. Kumar, "Optimal Location of UPQC in Fourteen Bus Distribution Network for Power Quality Improvement," 2020 International Conference on Renewable Energy Integration into Smart Grids: A Multidisciplinary Approach to Technology Modelling and Simulation (ICREISG), Bhubaneswar, India, 2020.

[6] Seyed Abbas Taher and Seyed Ahmadreza Afsari,"Optimal Location and Sizing of UPQC in Distribution Networks Using Differential Evolution Algorithm", Mathematical Problems in Engineering,2012.

[7] S. Chandrakala Devi, B. Singh and S. Devassy, "Modified generalised integrator based control strategy for solar PV fed UPQC enabling power quality improvement," in IET Generation, Transmission \& Distribution, vol. 14, no. 16, pp. 3127-3138, 2182020.

[8] Madhu Mathi .M. A, Sasiraja .R. M, "Improvement of Power Quality in the Distribution System by Placement of UPQC", IJESC, Vol.7, no.5, 2017

[9] S. Devassy and B. Singh, "Design and Performance Analysis of Three-Phase Solar PV Integrated UPQC," IEEE Transactions on Industry Applications, vol. 54, no. 1, pp. 73-81, Jan.-Feb. 2018. doi: 10.1109/TIA.2017.2754983

[10] R. Rajarajan, Dr.R. Prakash, "Mitigation Of Voltage Sags And Stability Analysis Of Distribution System Based On Upqc Using Substantial Transformation Intrinsic Algorithm (Stia)", Vol.7, no.4, 2020

[11] S. J. Alam and S. R. Arya, "Control of UPQC based on steady state linear Kalman filter for compensation of power quality problems," in Chinese Journal of Electrical Engineering, vol. 6, no. 2, pp. 52-65, June 2020.

[12] M. Laxmidevi Ramanaiah and Dr. M. Damodar Reddy,"Optimal Unified Power Quality Conditioner Allocation in Distribution Systems for Loss Minimization using Grey Wolf Optimization", vol.7, no. 11 , pp.48-53,2017

[13] S. Devassy and B. Singh, "Modified pq-Theory-Based Control of Solar-PV-Integrated UPQC-S," IEEE Transactions on Industry Applications, vol. 53, no. 5, pp. 5031-5040, Sept.-Oct. 2017. doi: 10.1109/TIA.2017.2714138

[14] Karuppiah Natarajan, Muthubalaji Sankaramoorthy and Anand Rajkumar, "Controlling the Power Loss in Radial Distribution Network by Optimally Placing UPQC through Reconfiguration Using Evolutionary Algorithms", International Journal of Pure and Applied Mathematics, VOl.118, no.16, 2018

[15] S. A. O. da Silva, L. B. G. Campanhol, G. M. Pelz and V. de Souza, "Comparative Performance Analysis Involving a Three-Phase UPQC Operating With Conventional and Dual/Inverted PowerLine Conditioning Strategies," IEEE Transactions on Power Electronics, vol. 35, no. 11, pp. 11652- 
Power Quality Enhancement by Optimally placing the UPQC in the Distribution System: A hybrid Optimization Model

11665 ,

Nov.

2020.

doi: 10.1109/TPEL.2020.2985322

[16] D.K. Tanti,M.K. Verma, Brijesh Singh, O.N. Mehrotra, "Optimal Placement of Custom Power Devices in Power System Network to Mitigate Voltage Sag under Faults", International Journal of Power Electronics and Drive System (IJPEDS),Vol.2, No.3, September 2012

[17] A. M. Rauf, A. V. Sant, V. Khadkikar and H. H. Zeineldin, "A Novel Ten-Switch Topology for Unified Power Quality Conditioner," IEEE Transactions on Power Electronics, vol. 31, no. 10, pp. 6937-6946, Oct. 2016.

[18] Sanjib Ganguly, "Impact of Unified Power-Quality Conditioner Allocation on Line Loading, Losses, and Voltage Stability of Radial Distribution Systems", IEEE TRANSACTIONS ON POWER DELIVERY, 2014

[19] S. R. Choudhury, A. Das, S. Anand, S. Tungare and Y. Sonawane, "Adaptive shunt filtering control of UPQC for increased nonlinear loads," in IET Power Electronics, vol. 12, no. 2, pp. 330-336, 2022019. doi: 10.1049/iet-pel.2018.5458

[20] K. Pavani, Dr. A. Lakshmi Devi, "Reactive Power Compensation of Distribution Networks with Unified Power Quality Conditioner Using Multi-Objective Particle Swarm Optimization", IJIREEICE, Vol. 3,2015

[21] Shahrzad Saremi, Seyedali Mirjalili, Andrew Lewis, "Grasshopper Optimisation Algorithm: Theory and application", Advances in Engineering Software, Vol.105, pp.30-47, 2017

[22] JohnMcCall, "Genetic algorithms for modelling and optimisation", Journal of Computational and Applied Mathematics, vol. 184, no. 1, pp. 205-222, 2005.

[23] Seyedali Mirjalili, Seyed Mohammad Mirjalili, Andrew Lewis, "Grey Wolf Optimizer", Advances in Engineering Software, Vol.69, pp, 46-61, 2014.

[24] D. Karaboga B. Basturk, "On the performance of artificial bee colony (ABC) algorithm", Applied Soft Computing, vol. 8, no. 1, pp. 687-697, 2008.

[25] S. K. Dash and P. K. RAY, "A New PV-Open-UPQC Configuration for Voltage Sensitive Loads utilizing novel Adaptive Controllers," IEEE Transactions on Industrial Informatics. doi: 10.1109/TII.2020.2986308

[26] M. M. Annie Alphonsa and N. Mohana Sundaram, "A reformed grasshopper optimization with genetic principle for securing medical data", Journal of Information Security and Applications, Vol.47,pp.410-420,2019 